\title{
Ernst Otto Bräunche, Peter Steinbach (dir.), Stadt
} und Demokratie

Ostfildern, Thorbecke (Stadt in der Geschichte 38), 2014, 292 p., 29,00€.

\section{Pierre Monnet}

\section{CpenEdition}

\section{Journals}

Édition électronique

URL : http://journals.openedition.org/ifha/8525

DOI : 10.4000/ifha.8525

ISSN : 2198-8943

Éditeur

IFRA - Institut franco-allemand (sciences historiques et sociales)

Référence électronique

Pierre Monnet, «Ernst Otto Bräunche, Peter Steinbach (dir.), Stadt und Demokratie », Revue de l'IFHA [En ligne], Date de recension, mis en ligne le 01 janvier 2016, consulté le 22 septembre 2020. URL : http:// journals.openedition.org/ifha/8525; DOI : https://doi.org/10.4000/ifha.8525

Ce document a été généré automatiquement le 22 septembre 2020

(CIFHA 


\section{Ernst Otto Bräunche, Peter Steinbach (dir.), Stadt und Demokratie}

Ostfildern, Thorbecke (Stadt in der Geschichte 38), 2014, 292 p., 29,00€.

\section{Pierre Monnet}

Ce volume appartient à une série de publications éditées depuis 1977 par le cercle de recherche en histoire urbaine fondé en 1963 à Pforzheim. La collection intitulée «Stadt in der Geschichte » (la ville dans l'histoire), riche de 39 volumes à ce jour, rassemble les actes de colloques annuels thématiques réunissant des spécialistes de la ville autour de concepts ou de sujets transversaux, tels que ville et guerre, ville et théatre, ville et commerce, ville et communication, ville et droit, ... traités dans une approche diachronique ( $\mathrm{du}$ Moyen Âge à nos jours) et interdisciplinaire (littérature, art, architecture, urbanisme, histoire, sciences politiques, droit, sociologie).

Le présent volume s'intéresse à l'avenir d'une gestion locale et communale des villes, qui fut, depuis le Moyen Âge, constitutive en Europe de leur définition et de leur essor, dans un temps d'urbanisation massive, de compétition mondiale entre métropoles et mégalopoles, de circulations et d'échanges toujours plus complexes et déspatialisés, de défis environnementaux et naturels qui menacent le processus d'urbanisation luimême, de repli communautaire, ethnique et social au sein même des quartiers et des périphéries. Face à ces recompositions, à ces crises, à ces explosions qui vont jusqu'à mettre en cause l'existence même et la notion de ville, au moment où cette forme de vie est en passe de rassembler la moitié de la population mondiale, les auteurs entendent présenter un certain nombre de cas locaux et régionaux, il est vrai limités à la seule « vieille » Europe (hormis un article de Michael Silagi sur les mécanismes juridiques et institutionnels du gouvernement local aux États-Unis), illustrant la manière dont les autorités communales tentent d'articuler en ville la superposition, et parfois la contradiction, des échelles (locale, régionale, nationale, globale). En cela, et c'est la réussite de l'ouvrage malgré la juxtaposition de cas isolés et monographiques, qu'une conclusion aurait dû au moins relier ensemble, les contributions présentent de manière exemplaire les paradoxes auxquels de nombreuses autorités municipales doivent aujourd'hui faire face. On assiste en effet d'un côté à une prise grandissante de 
commandement sur les villes par les grandes régions à l'échelle européenne, à la mise en réseau des communications de tous types, à l'intervention des États, à l'action communautaire de l'Union européenne, aux stratégies multipolaires des grandes entreprises multinationales; tandis que s'affirme parallèlement, et pour une grande part en réaction, une demande de retour au niveau local, aux initiatives citoyennes de proximité, à une gestion décentralisée des problèmes, à une identité retrouvée. Sans remonter au-delà du XIX ${ }^{e}$ siècle (à l'exception de la contribution de Peter Fleischmann consacrée au fonctionnement de la constitution urbaine de Nuremberg à l'époque moderne), quelques études parviennent à montrer que ces phénomènes locaux de démocratie communale participative prennent appui sur une tradition qui dépasse les défis posés depuis quelques décennies par la globalisation : mouvements féministes des années 1900, actions paroissiales et caritatives, processus de référendum local, prise de conscience environnementale avaient dès le début $d u X X^{e}$ siècle préparé outils et concepts pour penser et agir localement.

La lecture du volume vaut surtout pour les problèmes posés et la sensibilité accordée au jeu d'échelles, deux apports qui compensent un peu, mais pas totalement, l'impression dominante d'une collection disparate de cas et de contextes. Seules une introduction et une conclusion, malheureusement absentes, auraient pu mettre en perspective le sujet traité, en plaçant le problème à un triple niveau d'analyse comparée. En premier lieu, pour l'Europe, la France, l'Angleterre, la Suisse, l'Allemagne, les Pays-Bas ici traités n'ont pas historiquement le même tissu communal ou municipal. En deuxième lieu, il existe plusieurs Europes urbaines, et donc communales, où la ville et le principe démocratique s'articulent donc différemment: des cas empruntés aux pays méditerranéens, ou à l'Europe centrale ou orientale, auraient abouti à d'autres configurations. Enfin, et en troisième lieu, l'Europe n'est plus qu'un petit morceau d'un monde qui l'englobe et souvent l'ébranle, parce que ses villes assagies, historiques, aménagées, vieillissantes, présentent de moins en moins de traits communs avec les mégalopoles chaotiques, fourmillantes, expansives d'Amérique du Sud, d'Afrique ou d'Asie, lors même qu'un grand nombre d'entre elles avaient fonctionné, jusqu'au milieu $\mathrm{du} \mathrm{XX}^{\mathrm{e}}$ siècle, comme des villes dupliquées et exportées par la colonisation européenne du monde. La menace de divorce entre l'Europe et le reste du globe comporte aussi une dimension urbaine. Beau sujet donc que celui des rapports entre ville et démocratie au niveau local, mais à explorer par-delà les temps et les espaces.

Vous trouverez la table des matières ici : http://d-nb.info/1049212843/04.

\section{INDEX}

Index chronologique : Époque contemporaine

Thèmes : Histoire des villes et des régions 
AUTEUR

PIERRE MONNET

EHESS, Paris et IFRA-SHS, Frankfurt am Main 